\title{
MIDDLE-LATENCY AUDITORY EVOKED POTENTIALS IN CHILDREN AT HIGH RISK FOR ALCOHOLISM
}

Authors: Socorro Rodríguez Holguín, Montserrat Corral, Fernando Cadaveira

This is the peer reviewed version of the following article: Rodríguez Holguín, S., Corral, M. \& Cadaveira, F. (2001). Middle-latency auditory evoked potentials in children at high risk for alcoholism. Neurophysiologie Clinique, 31, 40-47. doi: 10.1016/S09877053(00)00241-0

This article may be used for non-commercial purposes in accordance with Elsevier Terms and Conditions for Use of Self-Archived Versions 


\title{
Middle-latency auditory evoked potentials in children at high risk for alcoholism
}

\author{
Socorro Rodríguez Holguín¹, Montserrat Corral, Fernando Cadaveira \\ Departamento de Psicoloxía Clínica e Psicobioloxía, Universidade de Santiago de \\ Compostela, Galiza, Spain
}

\section{Summary}

Purpose. In the course of a high-risk study for alcoholism, the middle-latency auditory evoked potentials (MAEPs) of children of alcoholics were explored. Material and Methods. A series of auditory clicks $(0.1 \mathrm{~ms}, 60 \mathrm{~dB}$ SL, 1.1/s) were used to record the $\mathrm{Pa}$ and $\mathrm{Pb}$ peaks of the MAEPs in 15 children of alcoholics with a multigenerational family history of alcoholism, and 17 control subjects, ranging from 10 to 14 years of age. Results. The latency of $\mathrm{Pb}$ was shorter in the high-risk than in the control group, and there was also a significant risk group by age interaction on Pa latency. The amplitude of Pa was smaller in the children of alcoholics. Conclusions. The characteristics of the MAEPs of the high-risk subjects did not match the pattern of abnormalities previously observed in chronic alcoholics, which are supposed to be a consequence of the neurotoxic effects of ethanol. Nonetheless, the results showed significant differences in MAEPs between children of alcoholics and controls, pointing to an anomalous pattern of information transmission from thalamus to cortex that should be further analyzed using larger samples in a broader age range.

Keywords: alcoholism / children of alcoholics / event-related potentials / high risk / middle-auditory evoked responses

(MAEPs)

\footnotetext{
${ }^{1}$ Correspondence author

Received 21 December 1999; accepted in revised form 2 August 2000
}

\section{Post-print (final draft post-refereeing)}


Potentiels évoqués auditifs de latence moyenne chez les enfants d'alcooliques.

\section{Résumé}

Objectifs. Étudier le risque possible d'alcoolisme chez des enfants d'alcooliques par l'enregistrement des potentiels évoqués auditifs de latence moyenne (PEALM). Matériel et méthodes. Dans le but d'enregistrer les composantes $\mathrm{Pa}$ et $\mathrm{Pb}$, une série de clicks (0.1 ms, $60 \mathrm{~dB}$ S.L, 1.1/s) a été délivrée à deux populations d'enfants âgés de 10 à 14 ans: 17 enfants-témoins et 15 enfants faisant partie d'une famille d'alcooliques. Résultats. La latence du Pb était raccourcie chez les enfants d'alcooliques. L'amplitude du Pa était plus petite et il y avait une interaction significative âge/groupe sur la latence de ce potentiel chez ces enfants. Conclusions. Les PEALM des sujets à haut risque ne présentent pas les mêmes anomalies que celles observées précédemment chez des alcooliques chroniques, qui sont une conséquence des effets neurotoxiques de l'alcool. Cependant, les résultats montrent des différences significatives des PEALM entre les enfants d'alcooliques et les enfants contrôles, suggérant une anomalie dans la transmission d'informations du thalamus au cortex. Cette analyse devra être approfondie grâce à des échantillons plus grands et un panel d'âges plus important.

Mots-clé: alcoolisme / enfants d'alcooliques / potentiels évoqués auditifs de latence moyenne (PEALM) / risque 


\section{Introduction}

Research into alcoholism has extensively employed psychophsysiological and neurophysiological measures with the aim of determining the effects of chronic alcohol abuse on the function of the nervous system and identifying vulnerability markers that could differentiate those subjects liable to develop alcoholism.

The spontaneous EEG activity as well as sensory evoked potentials and cognitive event-related potentials have been used to assess alcoholic patients. In subjects at familial risk for alcoholism, both spontaneous EEG and event-related potentials (mostly P300) have been studied as genetic vulnerability markers, so long as abnormalities observed in abstinent alcoholics are also present in children of alcoholics (for review see [5]). Early evoked potentials (EPs) have been less employed once it was reported that abnormalities affecting auditory brainstem evoked responses in alcoholics were not observable in children of an alcoholic father [6]. The fact that some of the anomalous electrophysiological characteristics first found in chronic alcoholics have been identified in their alcohol-naive relatives $[7,8,20,32,36]$ indicates that they are not only a result of the neurotoxic effects of substance abuse, and might be assessed as putative of electrophysiological markers for the development of alcoholism.

Although the EPs' abnormalities have been reported in alcoholics for early [9, 13, $14]$ and late [13, 15, 31] components in the auditory modality, few studies have assessed the middle-latency auditory evoked potentials (MAEPs) in relation to alcoholism. In a previous study at our laboratory, the $\mathrm{Na}$ and $\mathrm{Pa}$ components of the MAEPs were assessed in a group of abstinent alcoholics and matched controls [16]. Alcoholics presented shorter latencies of $\mathrm{Na}$ and $\mathrm{Pa}$ than controls, which were interpreted as the result of a disinhibitory effect of decreased GABAergic activity at the thalamic level, induced by the chronic exposure to alcohol. These results were subsequently confirmed in a study in animals with a long period of chronic ethanol intake [18].

Although the MAEPs' abnormalities were initially attributed to the neurotoxic consequences of alcohol, both deficits in inhibition and GABAergic function anomalies have been related to genetic vulnerability to alcoholism: deficits in electrophysiological inhibition have been proposed as the cause of abnormalities in other components of event-related potentials, such as P3b and P3a amplitude reductions, both in alcoholics and their children [30,33]. Autonomic psychophysiological studies also point to problems with inhibition of the information input, indicated by the cardiac hyperreactivity to stressful and novel stimuli [29]. Furthermore, genetic differences in GABAA receptor function have been proposed as mediating differences in the responsiveness to the sedative and anesthesic effects of alcohol between selective breeding rodents [1,37]. Then, it was 
considered of interest to explore these middle-latency responses in children of alcoholic parents when research into high risk for alcoholism was initiated in our group.

To assess the possibility that MAEPs were anomalous in high-risk subjects, the present study assessed a sample of young children of alcoholics with a multigenerational family history of alcoholism and controls.

\section{Methods and materials}

\section{Subjects}

The subjects were 32 children ranging from 10 to 14 years of age. The high risk (HR) group ( $N=15$, eight females, mean $=12.2 \pm 1.5$ years $)$ consisted of children of an alcoholic father with a high-density family history of alcoholism. The subjects in the HR group were selected from community treatment centres, where their fathers had been diagnosed and treated. All the alcoholic fathers met DSM-III-R [4] criteria for alcohol dependence (diagnosis made by the staff of the centres was corroborated during the selection interview). Those with a history of psychopathological problems other than secondary to alcoholism (according to the clinical history from the centres and the information collected during the selection interview) were excluded.

The family history of alcoholism was ascertained from fathers and mothers using the family history interview method. Only children of alcoholic fathers who had at least two other firstor second-degree alcoholic relatives were included. The control (CN) group $(\mathrm{N}=17$, ten females, mean $=11.8 \pm 1.4$ years $)$ consisted of children of non-alcoholic fathers without a family history of alcoholism. To guarantee homogeneity with regard to socio-demographic variables, control subjects were recruited from voluntary families from schools in the region within the same age range and socioeconomic status as those in the HR group. Control families who reported any problems with alcohol in firstor seconddegree relatives were excluded.

Other exclusion criteria were similar for the two groups, and included consumption of alcohol or other drugs, a history of psychopathological disorders, prenatal exposure to alcohol, developmental or school retardation, a positive neurological history, major medical problems, current medication, non-corrected sensory deficits, a family history of major mental diseases and problems of alcoholism in the mother. Information about inclusion and exclusion criteria was obtained through detailed semi-structured interviews with both the children and their fathers and mothers. The interviews were a translated and adapted version of the Semi-Structured Assessment 
for the Genetics of Alcoholism (SSAGA), versions for adults, children, adolescents and parents, as well as the Family History Assessment Module, designed by the Collaborative Study on the Genetics of Alcoholism (COGA) [10]. Questions about individual and familial psychopathological problems were based on DSM-III-R criteria and at least one other diagnostic classification system. Information was also obtained during the interviews about demographic data, family relations, school achievement and social activities.

The final sample was well matched on age, socioeconomic status and education (all subjects were enrolled in compulsory schooling and followed the grade according to age) between the groups (table I).

Table I. Demographic characteristics of control and high-risk groups.

\begin{tabular}{lccc}
\hline & Controls & High-Risk & $\mathrm{P}$ \\
\hline & $(N=17)$ & $(N=15)$ & \\
\hline Gender (f/m) & $10 / 7$ & $8 / 7$ & \\
Age (range) & $10-14$ & $10-14$ & \\
Mean (SD) & $11.8(1.4)$ & $12.2(1.5)$ & 0.412 \\
Education (years) & $6.1(1.3)$ & $7.0(1.3)$ & 0.059 \\
\hline
\end{tabular}

$\mathrm{f} / \mathrm{m}$ : female/male.

\section{Procedure}

Families who met requirements for the study were asked to participate; those who agreed signed a consent form, and then received an appointment for the assessment. When children arrived at the laboratory (early in the morning or in the afternoon), the members of staff showed them the laboratory and explained the contents and procedure of the assessment.

The subjects sat in a comfortable armchair, in an electrically-isolated, soundand light-attenuated laboratory. They received instructions to avoid moving during the tests and to direct their gaze to a point $1 \mathrm{~m}$ in front of their eyes where the stimuli were presented.

The stimuli were 400 rarefaction clicks $(0.1 \mathrm{~ms}$ duration) generated by the Stim module of a Neuroscan system and presented binaurally at a rate of $1.1 / \mathrm{s}$ through earphones, with an intensity $60 \mathrm{~dB} S \mathrm{SL}(60 \mathrm{~dB}$ above individual perceptual threshold, estimated using the method of ascending and descending limits with variation intervals of $0.75 \mathrm{~dB}$ SPL). The experimental paradigm (both stimuli characteristics and recording parameters) was selected to optimize the recordability of both $\mathrm{Pa}$ and $\mathrm{Pb}$. Tones are 
frequently used to obtain the $\mathrm{Pb}$ peak, and it has been reported that lowfrequency (500 $\mathrm{Hz}$ ), long-duration (60 ms) tone bursts are optimal to evoke $\mathrm{Pb}$ [26]; however, these parameters are not the best for obtaining $\mathrm{Pa}$, due to the long duration of the stimuli, which overlap with the earlier MAEP components. Clicks are the most common stimuli used to record $\mathrm{Pa}$ [35]. The inter-stimulus interval was also the result of a trade-off; a higher rate would be adequate to obtain $\mathrm{Pa}$, and it would permit us to use a larger number of stimuli per run; nonetheless, the recordability of $\mathrm{Pb}$ would be seriously impaired, due to amplitude decrease with repetition rates higher than $1 / \mathrm{s}$.

Electroencephalographic (EEG) activity was recorded at $\mathrm{Cz}$ and $\mathrm{Fz}$ (Standard Electrode Position Nomenclature [3, 21]) using tin electrodes, referred to linked earlobes, and with a forehead ground. Additional electrodes were used to monitor eye movements (supraorbital and the outer canthus of the left eye, referred to an infraorbital electrode). EEG activity was filtered (1-300 Hz) and amplified $50 \mathrm{~K}$ (Grass Neurodata Acquisition System, mod. 12, connected to a Neuro Scan, Inc. system for the analog-to-digital conversion and storage). Impedance values were kept at $5 \mathrm{~K} \Omega$ or below.

EEG was continuously sampled at a rate of $1500 \mathrm{~Hz}$. The signal was processed off-line: EEG was epoched from $10 \mathrm{~ms}$ pre-stimulus to $100 \mathrm{~ms}$ post-stimulus, digitally filtered at $10-300 \mathrm{~Hz}$, linear trends were eliminated and the signal was adjusted to $0 \mathrm{mV}$ prestimulus baseline and averaged (400 epochs). Moreover, to assess the reproducibility of the waveforms, the first 200 segments were averaged separately from the last 200 segments, and the intra-class correlation between the two traces were performed.

\section{Data analysis}

Peak latencies (ms) and amplitudes $(\mu \mathrm{V})$ of $\mathrm{Pa}$ and $\mathrm{Pb}$ at each electrode were measured with a semi-automatic peak detection program. First, a computer algorithm was used to search for the maximum negative peak amplitude for each electrode within the predefined latency window: $25-40$ and $50-80$ ms for $\mathrm{Pa}$ and $\mathrm{Pb}$ respectively. Peaks were then verified and adjusted by visual inspection, and those which were doubtful were revised by a second experienced member of the laboratory, blind to the risk status of the subject and the initial peak. Amplitude and latency values were automatically exported to an ASCII file for subsequent analyses.

Preliminary risk group (control, HR) by gender (male, female), and risk group (control, HR) by age (five levels, 10-14 years old) ANOVAs were made for determining the inclusion of gender and age variables in the design. As gender manifested no main effects or interactions in these analyses, both genders were considered jointly. Age showed an interaction with the risk group factor for the Pa latency, then it was considered

\section{Post-print (final draft post-refereeing)}


in the final analysis; this demographic factor had no effects on the other dependent variables, where it was excluded from subsequent analyses.

Then, the data were analyzed using $2 \times 2$ mixed-model ANOVAs, with electrode site $(F z, C z)$ as a within-subject factor and risk group (control, $H R$ ) as between-subjects factor for the amplitudes of $\mathrm{Pa}$ and $\mathrm{Pb}$, and the latency of $\mathrm{Pb}$, and using an Electrode ( $F z, C z$ ) by risk group (control, HR) by age (five levels, 10-14-years old) design for the latency of $\mathrm{Pa}$.

\section{Results}

\section{Reproducibility of the recordings and peak detectability}

The intra-class correlations between the two waveforms obtained from each subject were high both for the control $(\mathrm{Cz}$ mean $=.80 \pm .17, \mathrm{Fz}$ mean $=.87 \pm .12)$ and the high risk group $(\mathrm{Cz}$ mean $=.82 \pm .17, \mathrm{Fz}$ mean $=.85 \pm .18)$, and similar for the two groups $(\mathrm{t}=-$ 0.28 , NS at $\mathrm{Cz}$, and $\mathrm{t}=0.42$, NS at Fz), indicating an adequate similarity between the two segments of the run, and then an adequate reproducibility of the whole waveform.

The rate of detectability of the two main positive MAEP peaks were acceptable in the light of previous reports. Pa was observable in 20 subjects $(62.5 \%, 11$ controls and nine $\mathrm{HR}$ ) and $\mathrm{Pb}$ was measurable in 26 subjects ( $81.2 \%, 12$ controls and $14 \mathrm{HR}$ ). Both $\mathrm{Pa}$ and $\mathrm{Pb}$ jointly were observed in 18 of the 32 subjects (nine controls and nine HR). Four subjects (three controls and one HR) showed a waveform consisting of a broad positive deflection, peaking in the middle between the $\mathrm{Pa}$ and the $\mathrm{Pb}$ latency windows, and were excluded from the study; this morphology has been described previously [27, 34]. The waveforms recorded from four representative subjects are presented in figure 1.

\section{Risk group effects}

Figure 2 illustrates the grand averaged EP waveforms for the control and HR subjects where both $\mathrm{Pa}$ and $\mathrm{Pb}$ were measurable, and the descriptive data are summarized in table II. Significant effects affecting the risk group factor were observed for the amplitude of $\mathrm{Pa}(\mathrm{F}[1,18]=9.925, \mathrm{P}=0.006)$ and the latency of $\mathrm{Pb}(\mathrm{F}[1,24]=4.340, \mathrm{P}=0.048)$. The amplitude of $\mathrm{Pa}$ was smaller and the latency of $\mathrm{Pb}$ was shorter in the HR group than in the control group. Risk group and age factors manifested a significant interaction on the latency of $\mathrm{Pa}(\mathrm{F}[4,10]=31.124, \mathrm{P}=0.025)$, where the age factor also had a significant main effect $(F[4,10]=3.652, P=0.044)$. This interaction effect is illustrated

\section{Post-print (final draft post-refereeing)}


in figure 3, where it can be observed that the latency of Pa tends to diminish with age, and this effect was more prominent in the HR group than in the control group. It must be noted that the regression functions are non-significant, and they are only presented to illustrate the interaction effect. No risk group effects were observed on $\mathrm{Pb}$ amplitude. The within-subject factor electrode site was significant for the amplitude of $\mathrm{Pb}(\mathrm{F}[1,24]=$ $23.571, \mathrm{P}=0.000)$, and the latency of $\mathrm{Pa}(\mathrm{F}[1,10]=9.915, \mathrm{P}=0.010)$ and $\mathrm{Pb}(\mathrm{F}[1,24]$ $=4.870, \mathrm{P}=0.037)$.
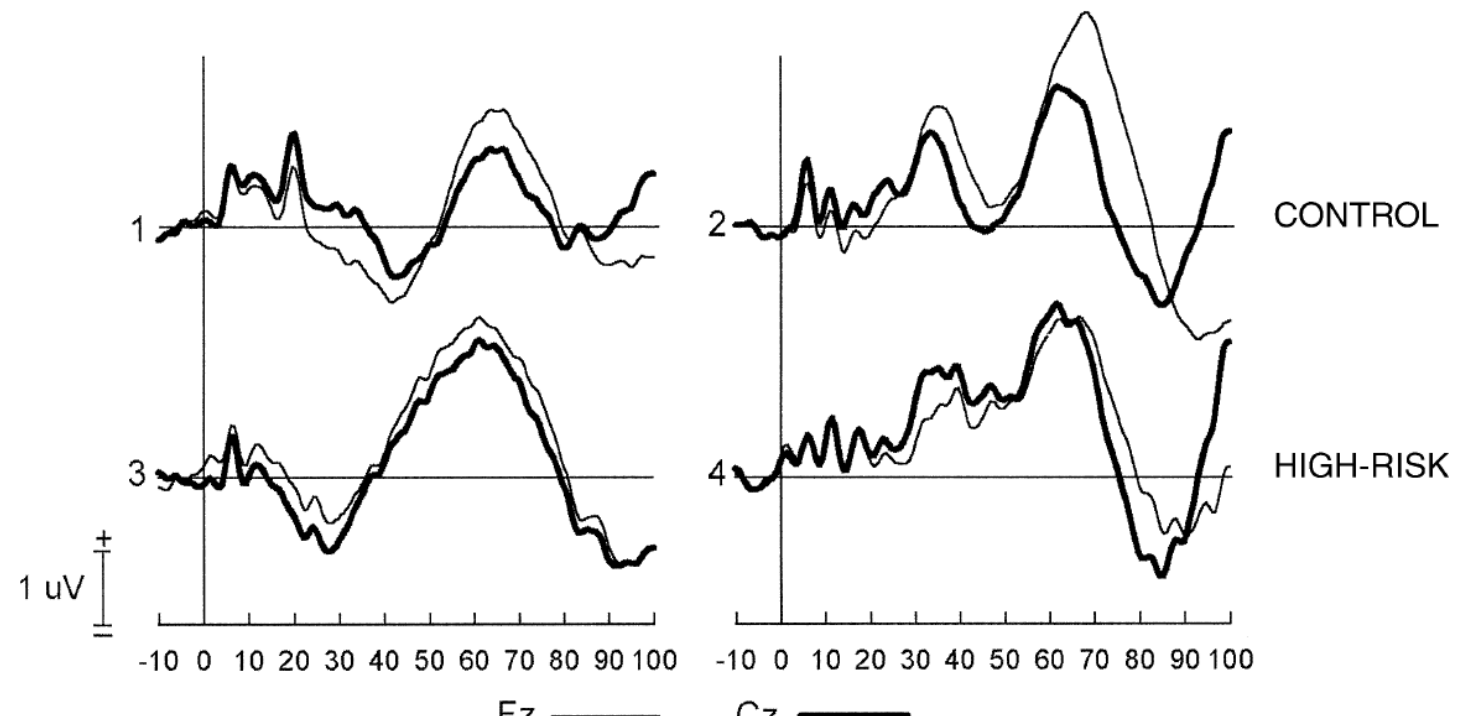

Figure 1. Individual waveforms from four representative subjects, two from the control group (top) and two from the high-risk group (bottom). The left waveforms are representative of those cases where only $\mathrm{Pb}$ was identified; the right waveforms represent those cases where both $\mathrm{Pa}$ and $\mathrm{Pb}$ were identified.
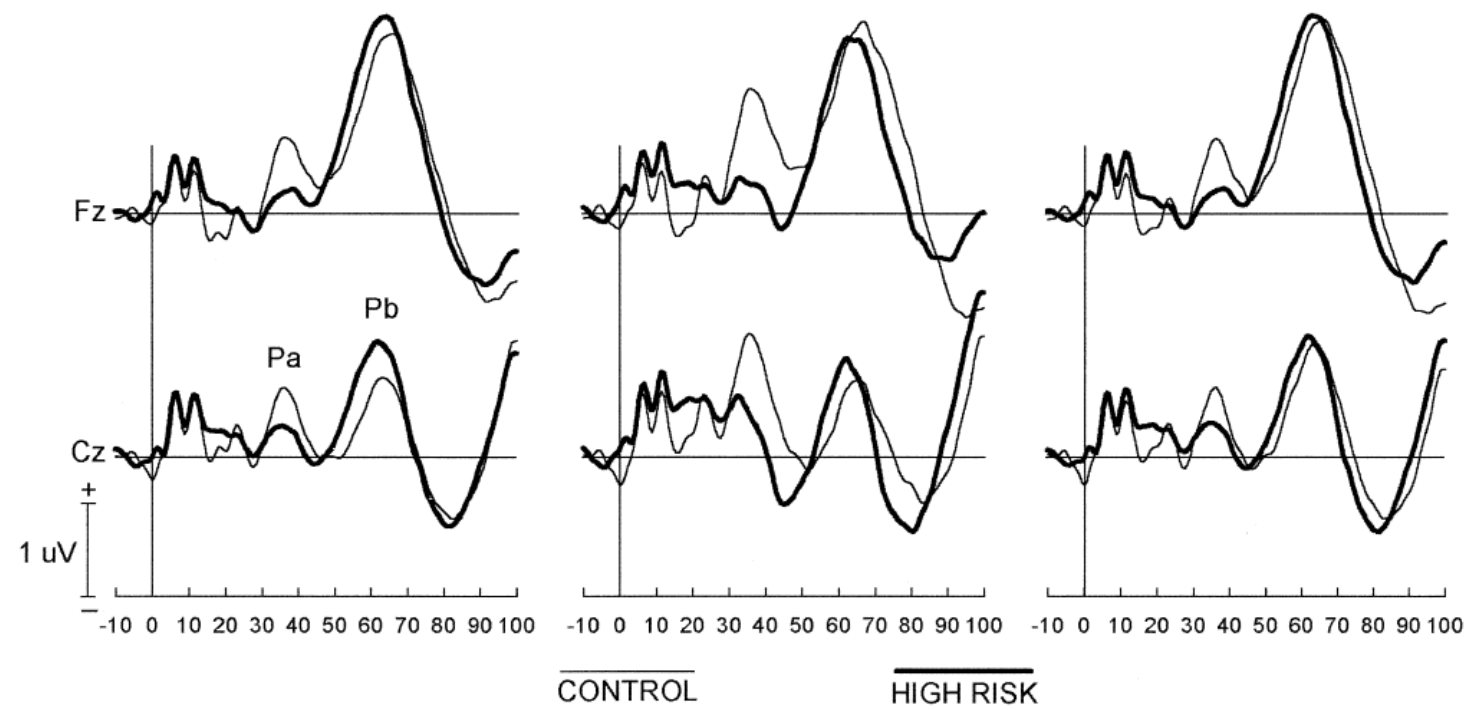

Figure 2. Grand mean waveforms of the MAEPs for the control and the high-risk groups, including the total sample (left), those subjects who entered the Pa ANOVA (center) and those who entered the $\mathrm{Pb}$ ANOVA (right). 
Table II. Mean (SD) amplitude $(\mu \mathrm{V})$ and latency (ms) values for the $\mathrm{Pa}$ and $\mathrm{Pb}$ peaks at $\mathrm{Fz}$ and $\mathrm{Cz}$ in the control and high-risk groups.

\begin{tabular}{ccccccccc}
\hline & \multicolumn{4}{c}{ Control } & & \multicolumn{3}{c}{ High-Risk } \\
\cline { 1 - 1 } \cline { 7 - 9 } & & $\mathrm{N}$ & Amplitude & Latency & & $\mathrm{N}$ & Amplitude & Latency \\
\hline $\mathrm{Pa}$ & $\mathrm{Fz}$ & 11 & $1.44(0.53)$ & $36.05(1.60)$ & & 9 & $0.52(0.75)$ & $35.31(3.71)$ \\
& $\mathrm{Cz}$ & 11 & $1.43(0.72)$ & $35.67(1.59)$ & & 9 & $0.65(0.82)$ & $35.17(3.78)$ \\
\hline $\mathrm{Pb}$ & $\mathrm{Fz}$ & 12 & $2.36(0.54)$ & $65.21(3.83)$ & & 14 & $2.22(1.41)$ & $62.90(2.30)$ \\
& $\mathrm{Cz}$ & 12 & $1.47(0.63)$ & $65.17(3.92)$ & & 14 & $1.44(1.10)$ & $62.36(2.39)$ \\
\hline
\end{tabular}

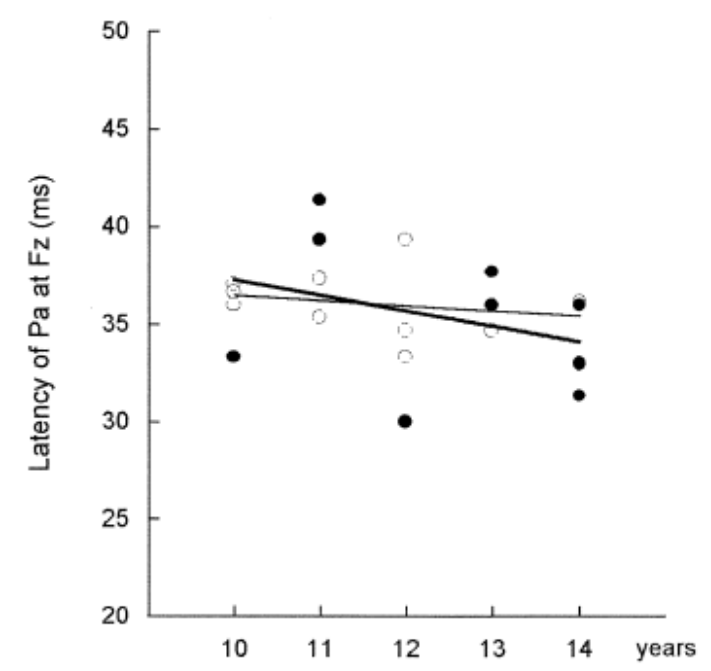

$\overline{\text { HIGH RISK }}$

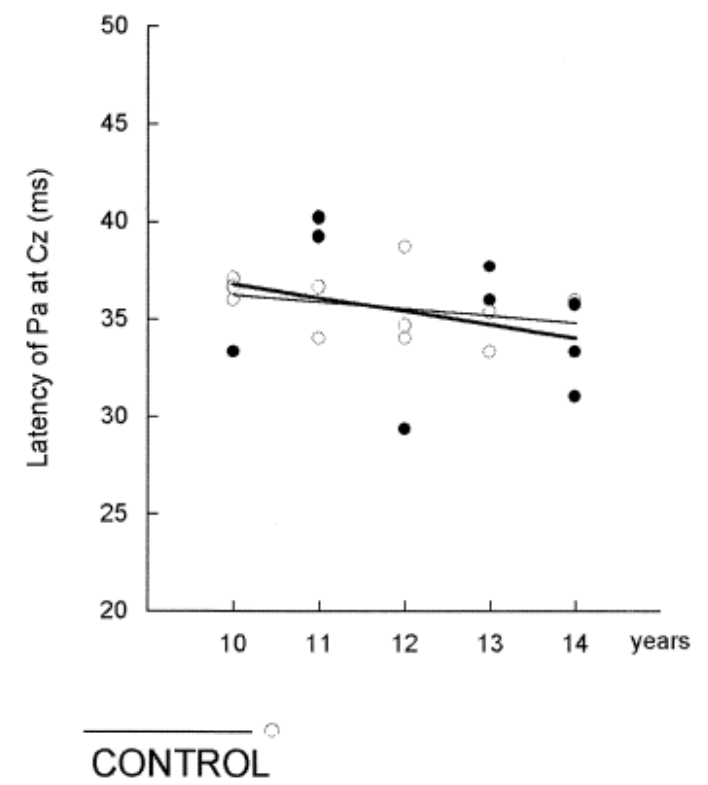

Figure 3. Graph illustration of the interaction effect between groups (control/high-risk) and age on the latency of $\mathrm{Pa}$.

\section{Discussion}

The results of the present study indicate significant differences between children of alcoholics with a multigenerational family of alcoholism and normal controls in the middle-latency auditory evoked response. Both the $\mathrm{Pa}$ and $\mathrm{Pb}$ peaks showed some kind of risk group effect. The latencies of $\mathrm{Pb}$ were shorter for the $\mathrm{HR}$ than for the control children, and the latency of $\mathrm{Pa}$ manifested a risk group by age interaction. Also, the $\mathrm{Pa}$ amplitude appeared significantly smaller in the high risk group.

The MAEP waveforms showed a good reproducibility, although the complete set of components (Na-PaNb-Pb) was not detected in all the children. Probably the 
percentage of detectability would have been increased by using a higher number of stimuli; nonetheless, the rate of $62 \%$ for $\mathrm{Pa}$ and $81 \%$ for $\mathrm{Pb}$ is in the range of other reports. Kraus et al. stated that $\mathrm{Pa}$ detectability was less than $50 \%$ under 10 years of age and 60-100\% over 10 [23]; in another study Kraus et al. [24] present their data in a figure showing around $80 \%$ detectability in the 10-15-year-old group; Tucker and Ruth [35] report a prevalence of $\mathrm{Pa}$ of $90 \%$ in 9-12-year-old subjects; Suzuki and Hirabayashi [34] describe that in 8-11-year-old subjects $\mathrm{Pa}$ reachs the adult range of latency, and the latter part of the waveform is still similar to that of young children. With regard to $\mathrm{Pb}$, Nelson et al. [26] found a recordable $\mathrm{Pb}$ in six out of nine 10-14-year-old children using a stimulation rate of $1.1 / \mathrm{s}$.

The finding of shorter latency of $\mathrm{Pb}$ cannot be compared with other studies, because to our knowledge there are no previous reports asssessing this MAEP component in alcoholics or high-risk subjects. The neural origin of $\mathrm{Pb}$ has been first related to the reticular activating system projections to the thalamic intralaminar nuclei $[11,17]$, and more recently to cortical generators in the primary auditory cortex [12, 25], with the cortical generators representing probably the main contribution to scalp recordings. $\mathrm{Pb}$ amplitude is sensitive to changes in arousal level and it has been related to preattentional gating mechanisms $[11,19,38]$. No basic studies have been focused on the functional significance of the temporal dynamics of $\mathrm{Pb}$, which would help to interpret the earlier resolution of this peak in high-risk subjects compared to controls.

Pa latency manifested a significant interaction between the risk group factor and age. It is difficult, from these preliminary results, to intrepret this interaction and its relation with the familial vulnerability to alcoholism. The shortening of $\mathrm{Pa}$ latency is a normal process during development $[34,35]$, which at this study appeared more pronounced in the high-risk group. This could indicate either a different rhythm of development between the groups, or a progression toward significant shorter Pa latency in the children of alcoholics compared with control population at the end of adolescence. This last possibility would be consistent with the shorter Pb latency in the high-risk group at the present study; it would also be reminiscent of the shorter $\mathrm{Na}$ and $\mathrm{Pa}$ latencies previously found in both chronic alcoholics [16] and animal models of alcoholism [18], and may indicate the presence of anomalous information transmission along the thalamocortical pathways previous to alcohol abuse. Although robust conclusions are prevented by the small size of the sample, and the limited age range (10-14 years), the results in our opinion warrant continous investigation focused on this MAEP component.

A second significant difference between the two risk groups concerned the amplitude of $\mathrm{Pa}$. The decreased voltage of this component in the high-risk group was a 
statistically robust effect and an unexpected finding, inasmuch as abstinent chronic alcoholics have been previously reported to presented slightly enhanced $\mathrm{Na}-\mathrm{Pa}$ amplitude [16]. Methodological differences between the two studies do not appear to be the cause of this discrepancy. Increases in $\mathrm{Pa}$ or $\mathrm{Na}-\mathrm{Pa}$ amplitudes have been reported in other clinical populations apart from alcoholics, such as Alzheimer patients [28], prefontal damage [22], and also in normal aging [2], and have been usually related with deficits in inhibitory processes controlling the ascending information from thalamus to cortex. Due to deficits in electrophysiological inhibition, which have been previously proposed in children of alcoholics, a larger $\mathrm{Pa}$ amplitude was expected in the high-risk group. These unexpected results, to be taken cautiously pending replication in future studies, may lead one to speculate that alcohol abuse in adults might in part be understood in terms of pharmacological compensation of a previously anomalous neural functioning.

In summary, the results of this preliminary report showed differences between children of alcoholics with a multigenerational family history of alcoholism and controls in the middle-latency evoked responses. The differences appeared in the latency of $\mathrm{Pb}$, the changes in $\mathrm{Pa}$ latency with age, and the amplitude of $\mathrm{Pa}$. The characteristics of the MAEPs of the high-risk subjects did not match the pattern of abnormalities previously observed in chronic alcoholics. Nonetheless, the results pointed to the presence of differences between children of alcoholics and controls that might be further analyzed with larger samples covering a wider range of ages.

\section{Acknowledgements}

This research was supported by the Spanish Ministerio de Educación y Cultura (DGICYT) grant PB95-0856. We thank the staff of UTA at the Hospital Xeral de Santiago de Compostela, Asociación de Ex-Alcohólicos de A Coruña and Asociación Viguesa de Alcohología for their help in recruiting the sample.

\section{References}

1 Allan AM, Mayes GG, Draski LJ. Gammaaminobutyric acidactivated chloride channels in rats selectively bred for differential acute sensitivity to alcohol. Alcohol Clin Exp Res 1991;15: 212-8.

2 Amenedo E, Díaz F. Effects of aging on middle-latency auditory evoked potentials: a cross-sectional study. Biol Psychiatry 1998; 43: 210-9.

\section{Post-print (final draft post-refereeing)}


3 American Electroencephalographic Society. American Electroencephalographic Society guidelines for standard electrode position nomenclature. J Clin Neurophysiol 1991;8: 200-2.

4 American Psychiatric Association. Diagnostic and statistical manual of mental disorders, 3rd ed., rev. Washington DC: American Psychiatric Press; 1987.

5 Begleiter $\mathrm{H}$, Porjesz B. Neurophysiological phenotypic factors in the development of alcoholism. In: Begleiter H, Kissin B, Eds. Alcohol and alcoholism. Vol 1. The genetics of alcoholism. New York: Oxford University Press; 1995. p. 269-93.

6 Begleiter H, Porjesz B, Bihari B. Auditory brainstem potentials in son of alcoholic fathers. Alcohol Clin Exp Res 1987; 11: 477-80.

7 Begleiter H, Porjesz B, Bihari B, Kissin B. Event-related brain potentials in boys at risk for alcoholism. Science 1984; 255: 1493-6.

8 Begleiter H, Porjesz B, Rawlings R, Eckardt M. Auditory recovery function and P3 in boys at risk for alcoholism. Alcohol 1987;4: 315-21.

9 Begleiter H, Porjesz B, Chou CL. Auditory brain-stem potentials in chronic alcoholics. Science 1981; 211: 1064-6.

10 Bucholz KK, Cadoret R, Cloninger CR, Dinwiddie SH, Hesselbrock VM, Nurnberger $\mathrm{JI}$, et al. A new, semi-structured psychiatric interview for use in genetic linkage studies: a report of the reliability of the SSAGA. J Stud Alcohol 1994; 55: 149-58.

11 Buchwald JS, Rubinstein EH, Schwafel J, Strandburg RJ. Midlatency auditory evoked responses: differential effects of a cholinergic agonist and antagonist. Electroencephalogr Clin Neurophysiol 1991; 80: 303-9.

12 Cacace AT, Satya-Murti S, Wolpaw JR. Human middlelatency auditory evoked potentials: vertex and temporal components. Electroencephalogr Clin Neurophysiol 1990; 77: 6-18.

13 Cadaveira F, Grau C, Roso M, Sánchez-Turet M. Multimodality exploration of eventrelated potentials in chronic alcoholics. Alcohol Clin Exp Res 1991; 15: 607-11.

14 Chan YW, McLeod JG, Tuck RR, Feary PA. Brain stem auditory evoked responses in chronic alcoholics. J Neurol Neurosurg Psychiatry 1985; 48: 348-53.

15 Cohen HL, Wang W, Porjesz B, Begleiter H. Auditory P300 in young alcoholics: regional response characteristics. Alcohol Clin Exp Res 1995; 19: 469-75.

16 Díaz F, Cadaveira F, Grau C. Shortand middle-latency auditory evoked potentials in abstinent chronic alcoholics: preliminary findings. Electroencephalogr Clin Neurophysiol 1990; 77: 145-50.

17 Erwin RJ, Buchwald JS. Midlatency audiotry evoked responses in the human and the cat model. In: Johnson R, Rohrbaugh JW, Parasuraman R, Eds. Current trends in event-related potential research (EEG Suppl 40). Amsterdam: Elsevier Science; 1987. p. 461-7.

18 Floyd EA, Reasor JD, Moore EL, Rucker HK. Effects of chronic ethanol ingestion on mid-latency auditory evoked potentials depend on length of exposure. Alcohol 1997; 14: 269-79.

19 Freedman R, Adler LE, Gerhardt GA, Waldo MC, Baker N, Rose GM, et al. Neurobiological studies of sensory gating in schizophrenia. Schizophr Bull 1987; 13: 669-78.

20 Hill SY, Steinhauer SR, Lowers L, Locke J. Eight-year follow-up of P300 and clinical outcome in children from high-risk for alcoholism families. Biol Psychiatry 1995; 37: 823-7. 
21 Jasper $\mathrm{H}$. The ten twenty electrode system of the International Federation. Electroencephalogr Clin Neurophysiol 1958; 10: 371-5.

22 Knight RT, Scabini D, Woods DL. Prefrontal cortex gating of auditory transmission in humans. Brain Res 1989; 504: 338-42.

23 Kraus N, Smith DI, Reed N, Stein L, Cartee C. Auditory middle latency responses in children: effects of age and diagnostic category. Electroencephalogr Clin Neurophysiol 1985; 62: 343-51.

24 Kraus N, Reed N, Smith DI, Stein L, Cartee C. High-pass filter settings affect the detectability of MLRs in humans. Electroencephalogr Clin Neurophysiol 1987: 234-6.

25 Liégeois-Chauvel C, Musolino A, Badier JM, Marquis P, Chauvel P. Evoked potentials recorded from the auditory cortex in man: evaluation and topography of the middle latency components. Electroencephalogr Clin Neurophysiol 1994; 92: 204-14.

26 Nelson MD, Hall JW, Jacobson GP. Factors affecting the recordability of auditory evoked response component $\mathrm{Pb}$ (P1). J Am Acad Audiol 1997;8: 89-99.

27 Özdamar Ö, Kraus N. Auditory middle-latency responses in humans. Audiol 1987; 22 : 34-49.

28 Phillips NA, Connolly JF, Mate-Kole CC, Gray J. Individual differences in auditory middle-latency responses in elderly adults and patients with Alzheimer's disease. Int J Psychophysiol 1997; 27: 125-36.

29 Pihl RO, Finn PR, Peterson JB. Autonomic hiperreactivity and risk for alcoholism. Prog Neuropsychopharmacol Biol Psychiatry 1989; 13: 489-96.

30 Porjesz $\mathrm{B}$, Begleiter $\mathrm{H}$. Effects of alcohol on electrophysiological activity of the brain. In: Begleiter H, Kissin B, Eds. Alcohol and alcoholism. Vol 2. The pharmacology of alcohol and alcohol dependence. New York: Oxford University Press; 1996. p. 207-47.

31 Realmuto G, Begleiter H, Odencrantz J, Porjesz B. Event-related potential evidence of dysfunction in automatic processing in abstinent alcoholics. Biol Psychiatry 1993; 33: 594-601.

32 Rodríguez Holguín S, Corral M, Cadaveira F. Event-related potentials elicited by a visual continuous performance task in children of alcoholics. Alcohol 1999; 19: 23-30.

33 Rodríguez Holguín S, Porjesz B, Chorlian DB, Polich J, Begleiter H. Visual P3a in male subjects at high risk for alcoholism. Biol Psychiatry 1999; 46: 281-91.

34 Suzuki T, Hirabayashi M. Age related morphological changes in auditory middlelatency response. Audiology 1987; 26: 312-20.

35 Tucker DA, Ruth RA. Effects of age, signal level, and signal rate on the auditory middle latency response. J Am Acad Audiol 1996;7: 83-91.

36 Van-der-Stelt O, Geesken R, Gunning WB, Snel J, Kok A. P3 scalp topography to target and novel visual stimuli in children of alcoholics. Alcohol 1998; 15: 119-36.

37 Wafford KA, Burnett DM, Dunwiddie TV, Harris RA. Genetic differences in the ethanol sensitivity of GABAA receptors expressed in Xenopus oocytes. Science 1990; 249: 291-3.

38 White PM, Yee CM. Effects of attentional and stressor manipulations on the P50 gating response. Psychophysiology 1997; 34: 703-11. 